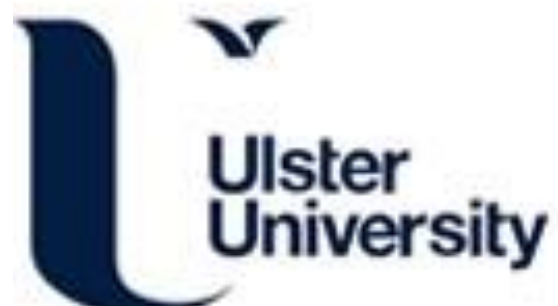

Extraction of triterpenoid compounds from Ganoderma Lucidum spore powder through a dual-mode sonication process

Shen, S. F., Zhu, L. F., Wu, Z., Wang, G., Ahmad, Z., \& Chang, M. W. (2020). Extraction of triterpenoid compounds from Ganoderma Lucidum spore powder through a dual-mode sonication process. Drug Development and Industrial Pharmacy, 46(6), 963-974. https://doi.org/10.1080/03639045.2020.1764022

Link to publication record in Ulster University Research Portal

Published in:

Drug Development and Industrial Pharmacy

Publication Status:

Published online: 13/05/2020

DOI:

10.1080/03639045.2020.1764022

Document Version

Author Accepted version

\section{General rights}

Copyright for the publications made accessible via Ulster University's Research Portal is retained by the author(s) and / or other copyright owners and it is a condition of accessing these publications that users recognise and abide by the legal requirements associated with these rights.

\section{Take down policy}

The Research Portal is Ulster University's institutional repository that provides access to Ulster's research outputs. Every effort has been made to ensure that content in the Research Portal does not infringe any person's rights, or applicable UK laws. If you discover content in the Research Portal that you believe breaches copyright or violates any law, please contact pure-support@ulster.ac.uk. 


\title{
Extraction of Triterpenoid compounds from Ganoderma Lucidum Spore Powder through a dual-mode sonication process
}

\author{
Shuang-Fei Shen ${ }^{\text {a, b }}$, Li-Fang Zhu ${ }^{\text {a, b }}$, Zijing $\mathrm{Wu}^{\mathrm{c}}$, Guangkun Wang ${ }^{\mathrm{c}}$, Zeeshan \\ Ahmad $^{\text {d }}$, Ming-Wei Chang ${ }^{\text {a, e* }}$
}

${ }^{a}$ Key Laboratory for Biomedical Engineering of Education Ministry of China, Zhejiang University, Hangzhou, 310027, P. R. China.

${ }^{\mathrm{b}}$ Zhejiang Provincial Key Laboratory of Cardio-Cerebral Vascular Detection Technology and Medicinal Effectiveness Appraisal, Zhejiang University, Hangzhou, 310027, P. R. China.

${ }^{\mathrm{c}}$ Tianhe Agricultural Group, No. 328, Jianchi West Road, Longquan City, Zhejiang, 323700, P. R. China.

${ }^{\mathrm{d}}$ Leicester School of Pharmacy, De Montfort University, The Gateway, Leicester, LE1 9BH, UK.

${ }^{\mathrm{e} N a n o t e c h n o l o g y}$ and Integrated Bioengineering Centre, University of Ulster, Jordanstown Campus, Newtownabbey, BT37 0QB, Northern Ireland, UK

* corresponding author: Ming-Wei Chang, Ph.D.

Tel: +44 289536 7142, Email: m.chang@ulster .ac.uk 


\begin{abstract}
Development of drug products from natural sources enable advantageous treatment and therapy options. Bioactive compounds in Ganoderma lucidum spore powder (GLSP) are known for vast antibacterial, antioxidant and anti-cancer properties. Herein, we studied the use of dual-probe ultrasound to extract triterpenoids from GLSP and further investigated the bioactivity of resulting products. FTIR results confirm the presence of key peaks although dual-probe ultrasound varied extraction efficacy. Response surface methodology (RSM) was used to optimize extraction conditions (55:28 for solvent to solid ratio, 10.38 seconds of ultrasound time and $94 \% \mathrm{v} / \mathrm{v}$ of ethanol concentration). HPLC-Q-TOF-MS confirmed the presence of 9 different compounds and in vitro tests confirm good biocompatibility. Extracts are shown to inhibit DPPH radicals, reaching a maximum $(61.09 \pm 1.38 \%)$ at triterpenoid concentrations of $600 \mu \mathrm{g} / \mathrm{mL}$. Dual-mode assisted extraction provides an enhanced approach for active embedded fiber production on a scale favorable to industry when using optimized process parameters. Furthermore, triterpenoid extracts show antibacterial properties on S. aureus and E. coli with potential in antibacterial and anticancer applications.
\end{abstract}

Keywords: Triterpenoids; dual-model ultrasound; antibacterial; antioxidant; biocompatibility. 


\section{Introduction}

There is increasing interest in the development and application of natural phytochemicals as potential chemo-preventive agents in the healthcare remit, in pharmaceuticals and cosmetics ${ }^{1-3}$. Some phytochemicals have been evaluated and their potential in clinical use has been successfully portrayed. For example, paclitaxel analogs and vince alkaloids have been used in chemotherapy for decades ${ }^{4}$. Ganoderma lucidum is a traditional medicine that is commonly used to promote health and longevity, especially in Asia ${ }^{5}$. It is used to in a range of applications including tumor treatment ${ }^{6}$, anti-aging effects ${ }^{7}$ and in the prevention of neurological diseases ${ }^{8}$. G. lucidum spore powder (GLSP) is the spores of the G. lucidum. These spores are small oval germ cells that are expelled from the fungi during growth and maturation ${ }^{9}$. They contain all the genetic material of G. lucidum and therefore have all the health benefits ${ }^{10}$. Recent research has confirmed that G. lucidum spores (GLS) have multiple functions including blocking histamine release, inhibiting the over-stimulated immune system, and regulating cell and humoral immunity ${ }^{11-13}$. These results demonstrate that GLS have a variety of physiological functions related to the diversity of its biologically active components 14,15 . GLS contains many biologically active ingredients such as triterpenoids, polysaccharides, alkaloids, amino acids, enzymes and proteins ${ }^{16,17}$. Triterpenoids, a main component of GLSP, have been found to have a wide range of pharmacological activity ${ }^{18}$. There are very few studies concerning extraction of 
triterpenoids from GLSP and therefore it is important to explore its constituents and bioactivity.

There are various methods that are used to extract compounds including but not limited to reflux, maceration and soxhlet extraction. Conventional extraction methods for triterpenoids are time consuming and utilize excessive volumes of solvent and achieve low extraction rate ${ }^{19}$. In contrast, ultrasound-assisted extraction (UAE) techniques present a sustainable alternative extraction method using less solvent and energy ${ }^{20}$. Acoustic cavitation induced by ultrasound is capable of breaking cell walls of plant matrix, enhancing the release of bioactive compounds from the matrix ${ }^{21}$. Ultrasonicassisted extraction has many advantages over more conventional methods, including but not limited to shorter processing times, reduced solvent usage, higher extraction rates, more economical extraction processes and improved product purity ${ }^{22}$. Process parameters and solvent parameters affecting the extraction rate of ultrasonic extraction include feed-to-liquid ratio, solvent concentration, ultrasound time and ultrasound frequency. Recently, multi-mode ultrasound has been presented as an effective method to improve product extraction rates ${ }^{23}$. While ultrasound extraction may be expected to improve the extraction yield, triterpenoid compounds obtained from GLSP using two different frequencies ultrasonic treatment for a higher extraction rate is needed.

Response Surface Methodology (RSM) is an effective statistical tool for optimizing complex processes ${ }^{24}$. It is widely used to optimize the extraction of polysaccharides ${ }^{25}$, anthocyanins ${ }^{26}$, phenolic compounds ${ }^{27}$, proteins ${ }^{28}$ and triterpenoids ${ }^{29}$ from different 
plant materials. However, RSM can be applied to optimize species-specific compound extraction using ultrasonic parameters (i.e. extraction temperature, power percentage and exposure time).

In this study, the main objective was to investigate the effect of UAE variables (solvent to material ratio, ultrasound time and concentration of ethanol) using two different frequency probes for ultrasound-assisted triterpenoids extraction from GLSP. Two different probe positions were assessed; parallel and perpendicular. The values of the variables were then optimized using RSM to obtain the maximum yield of total triterpenoids in GLSP. Subsequently, component detection and bioactivity characterization of the extracted compound was performed. In order to study triterpenoid antioxidant activity, a DPPH experiment was carried out and antibacterial activity was analyzed using the disk diffusion method. The biocompatibility of extracts to L929 cells and Hela cells was also examined.

\section{Materials and methods}

2.1 Materials and reagents

Dried GLSP was received from Tianhe Agriculture Group (Zhejiang, China). Ethanol and glacial acetic acid were purchased from Taicang Shanghai Test Reagent Co., Ltd. (Jiangsu, China). Perchloric acid was purchased from Shanghai Wokai Biotechnology Co., Ltd. (Shanghai, China). Oleanolic acid was purchased from Adamas-beta (Shanghai, China). Vanillic was purchased from Shanghai Aladdin Bio-Chem 
Technology Co., Ltd, LTD (Shanghai, China). All the reagents used were analytical grade.

\subsection{Ultrasound-assistant extraction}

In the study, two different frequency ultrasonic generators were used to assist in triterpenoids extraction. A schematic diagram of the experimental setup of dual ultrasound extraction device is shown in Figure 1. Two transducers, $U_{1}(\Phi=13 \mathrm{~mm}$, $20 \mathrm{kHz}, 200 \mathrm{~W}$, Sonifier 250, Branson Ultrasonics Co., Ltd) and $\mathrm{U}_{2}(13 \mathrm{~mm}, 15 \mathrm{kHz}$, 600 W, Shanghai Yanyong Ultrasonics Co., Ltd), were used.

In order to investigate effect of the position between two transducers, they were fixed at transvertical position $\mathrm{U}_{1}$ and $\mathrm{U}_{2}$. For parallel treatment, $\mathrm{U}_{2}$ was moved to the position of $\mathrm{U}_{2}{ }^{*}$, as shown in Figure 1. The metal container $(205 \times 205 \times 200 \mathrm{~mm})$ was filled with water. The effects of the relative position of the two probes were compared.

Four factors were selected to analysis their effect on the yield of triterpenoids from GLSP through single-factor experiments: 1) relative position of dual frequency, 2) solvent to material ratio, 3) ultrasound time, and 4) concentration of ethanol. During the entire experiment, when one factor was changed, the other three factors were kept constant. Different concentrations of ethanoic solutions were prepared by blending ethanol with distilled water.

\subsection{Fourier transform infrared spectroscopy}

Fourier Transform Infrared (FTIR) spectroscopy (IR Affinity 1, Shimadzu, Japan) was used to compare the effects of different number of ultrasound probes and relative 
position on the chemical structure of extract. Samples were prepared using the $\mathrm{KBr}$ pellet pressing method using $20 \mathrm{MPa}$ of pressure and were scanned across the range was $4000-400 \mathrm{~cm}^{-130}$.

\subsection{Experimental design}

\subsubsection{Box-Behnken Design}

Box-Behnken Design (BBD) was used to determine the optimal conditions of UAE. The study of the influence of all the defined independent variables was carried out using a one-factor-at-a-time program; to determine the initial range of the processing variables. Based on the above single-factor results, three major independent variables were selected: solvent to solid ratio (A), ultrasound time (B, min), ethanol concentration $(\mathrm{C}, \%)$. The independent variables and their related codes and levels are displayed in Table 1. The experimental design consisted of 12 factorial experiments and 5 replicates of the central point (Table 2). The yield of triterpenoids was selected as the response for the combination of independent variables given in Table 2. In order to minimize the unpredictable effects in the observed responses, experimental runs were random.

\subsubsection{Mathematical Model}

The response surface models were fitted by means of least-squares calculation using the following second-order polynomial equation:

$\mathrm{Y}=\mathrm{a}_{0}+\mathrm{b}_{1} \mathrm{~A}+\mathrm{b}_{2} \mathrm{~B}+\mathrm{b}_{3} \mathrm{C}+\mathrm{c}_{12} \mathrm{AB}+\mathrm{c}_{13} \mathrm{AC}+\mathrm{c}_{23} \mathrm{BC}+\mathrm{d}_{1} \mathrm{~A}^{2}+\mathrm{d}_{2} \mathrm{~B}^{2}+\mathrm{d}_{3} \mathrm{C}^{2}$

Where $\mathrm{Y}$ is the predicted response; $\mathrm{a}_{0}$ is the interception; $\mathrm{b}_{1}, \mathrm{~b}_{2}$ and $\mathrm{b}_{3}$ are the linear coefficients of solvent to solid ratio (A), ultrasound time (B) and ethanol concentration 
(C), respectively; $\mathrm{c}_{12}, \mathrm{c}_{13}$, and $\mathrm{c}_{23}$ are the interaction coefficient of solvent to solid ratio, ultrasound time and ethanol concentration, respectively; $d_{1}, d_{2}$ and $d_{3}$ are the squared coefficient of solvent to solid ratio, ultrasound time and ethanol concentration, respectively.

Statistical analysis was performed using the software Design Expert (Version 8.0.6, Stat-Ease Inc., Minneapolis, MN, USA). Additional confirmation experiments were subsequently conducted to verify the statistical experimental design.

\subsection{Determination of total triterpenoids content}

The total triterpenoids content was measured by the Vanillin-glacial acetic acid method

31. Oleanolic acid was used as a standard. A standard curve (for triterpenoids) was obtained using UV analysis at a wavelength of $545 \mathrm{~nm}$. The total content of triterpenoids was calculated from the standard curve. A linear correlation relationship between absorbance and concentration was obtained as shown in Figure 1b.

The equation for the linear relationship is as follows:

$A=6.22 C-0.0298,\left(R^{2}=0.998\right)$

Where $\mathrm{C}(\mathrm{mg} / \mathrm{mL})$ is the concentration of triterpenoids solution and $\mathrm{A}$ is the absorbance at $545 \mathrm{~nm}$.

Equation 2 was used to calculate the yield of triterpenoids:

$\mathrm{Y}=(\mathrm{A}+0.0298) / 6.22 \times \mathrm{v} / \mathrm{m} \times 100 \%(\% \mathrm{w} / \mathrm{w})$

Where $\mathrm{v}$ is the total volume of extraction solvent $(\mathrm{mL})$, and $\mathrm{m}$ is the mass of triterpenoid extract sample $(\mathrm{g})$. 


\subsection{HPLC-Q-TOF-MS analysis}

As stated in the literature ${ }^{32}$, in order to identify the compounds being extracted using ultrasound assisted method, a Fast High Performance Liquid Phase-Quadrupole Timeof-Flight (Q-TOF) Mass Spectrometer (AB Sciex Triple TOF 5600+, AB Sciex, USA) was used. The mass range $(\mathrm{m} / \mathrm{z})$ of the instrument was $50-10000 \mathrm{~m} / \mathrm{z}$, and the resolution was greater than 40000 .

2.7 1,1-diphenyl-2-picrylhydrazyl (DPPH) radical scavenging activity

A spectrophotometric method was used to analyze the antioxidant activity of triterpenoids on the basis of free radical DPPH according to previous papers with a slight modification ${ }^{33}$. Firstly, $0.2 \mathrm{mM} \mathrm{DPPH}$ and samples with different concentrations from 0 to $600 \mu \mathrm{g} / \mathrm{mL}$ were prepared in ethanol solution. Then equal amount $(100 \mu \mathrm{L})$ of DPPH and the sample was mixed. After $30 \mathrm{~min}$ at room temperature, the absorbance of all samples was measured at a wavelength of $517 \mathrm{~nm}$ using a microplate reader (spectra Max 190, Nano Drop, USA). The results were expressed as a percentage reduction absorbance shown by the sample with respect to the control DPPH solution (ethanol and DPPH solution).

The formula used to calculate this is as follows:

DPPH scavenging $(\%)=[($ control absorbance - sample absorbance $) /$ control absorbance] $\times 100$.

\subsection{Antimicrobial activity}


The antimicrobial activity of the extract of triterpenoids against Escherichia coli (NW1014 (8099), Nanjing Maojie Microbiology Technology CO. LTD, Jiangsu, China) and Staphylococcus aureus (CMCC(B)26003, Shanghai Luwei Microbial SCI. \& TECH. CO. LTD, China) was examined using the disc diffusion method ${ }^{34}$. Firstly, five circular paper pieces with diameters of $8 \mathrm{~mm}$ were placed on agar plates. Two different bacteria (which had been cultured for $24 \mathrm{~h}$ ) were inoculated on the agar plates.

Different volumes of extract $(2 \mu \mathrm{L}, 4 \mu \mathrm{L}, 6 \mu \mathrm{L}$, and $8 \mu \mathrm{L})$ were introduced to each paper disc; with the central disc void of extract to act as the control. The plates were incubated at $37^{\circ} \mathrm{C}$ for $24 \mathrm{~h}$. The diameter of the zone of inhibition around each paper was used to determine the susceptibility of the extract. Both experiments were performed five times in parallel and the values were expressed as mean \pm standard deviation (SD).

\subsection{Cell culture}

The L929 cell were cultured in a Modified Eagle's Medium (MEM, Gino Biomedical Technology Co., Ltd., China) supplemented with 10\% Fetal Bovine Serum (FBS, Gibco), 1\% antibiotics (Penicillin $100 \mathrm{U} / \mathrm{mL}$, Streptomycin $100 \mu \mathrm{g} / \mathrm{mL}$ ). The Hela cells were cultured in Dulbecco's Modified Eagle's Medium (DMEM, Corning, USA) supplemented with 10\% Fetal Bovine Serum (FBS, Gibco), 1\% antibiotics (Penicillin $100 \mathrm{U} / \mathrm{mL}$, Streptomycin $100 \mu \mathrm{g} / \mathrm{mL}$ ). All cells were cultured in an incubator in $5 \%$ $\mathrm{CO}_{2}$ at $37^{\circ} \mathrm{C}$.

2.10 Cell viability analysis (L929) 
The effect of triterpenoids on L929 cell viability with a CCK-8 assay was investigated. Firstly, different amounts of the triterpenoid extract were added to the MEM medium to prepare medicated medium with concentrations of $0.01,0.05,0.1,0.2,0.4,0.6,0.8$ $\mathrm{mg} / \mathrm{mL}$. L929 cells (grown in $\log$ phase) $(100 \mu \mathrm{L})$ were introduced into 96-well plates and cultured for $24 \mathrm{~h}$ to adhere the cells. The original medium was removed and the medium containing the triterpenoid extract was replaced and cultured for $24 \mathrm{~h}$.

The medium was mixed with CCK-8 at a ratio of 10:1. After $24 \mathrm{~h}$, the previous medium was removed and $100 \mu \mathrm{L}$ of the mixture was added to each well and the plate was cultured in an incubator. The absorbance was measured with a microplate reader at predetermined time points. The cell survival rate was calculated as follows:

Cell survival rate $=[(\mathrm{As}-\mathrm{Ab}) / \mathrm{Ac}-\mathrm{Ab})] \times 100 \%$

As: Experimental well (cell-containing medium, CCK-8, triterpenoid extract)

Ac: Control well (cell-containing medium, CCK-8, no triterpenoid extract)

Ab: Blank well (a medium free of cells and triterpenoid extract, CCK-8)

2.11 Cell morphology observation (L929)

As described previously ${ }^{35}$ cells were obtained using the same procedure as stated in 2.10. Following removal of the cells from the incubator, the medium was removed from the dish and the cells were rinsed with PBS. 4\% paraformaldehyde was then added and then were agitated for 60 minutes at $60 \mathrm{rpm} .0 .1 \%$ Triton was then introduced to the cells and they were agitated for an additional 5 minutes at 60rpm. Following this treatment, the cells were rinsed 3 times with PBS; 5 minutes each time. Finally, the 
cells were stained with two different fluorescent dyes; the cytoskeleton was stained with Phalloidin (P) for 20 minutes and $60 \mathrm{rpm}$ and the nucleus was stained with DAPI for 5 minutes at 60rpm. The final stained cells were then observed under a fluorescence microscope.

\subsection{Anticancer activity (Hela)}

The effect of triterpenoids on Hela cell viability was studied with a CCK-8 assay. The Hela cells were cultured in DMEM medium. The cell survival rate experimental set-up was as described in 2.10 and the Hela cell staining experiment steps were as described in 2.11 .

\subsection{Statistical analysis}

All experiments were performed in triplicate and the results were expressed as mean value \pm standard deviation. In this study, t-test and ANOVA tests were performed. The statistical analysis was carried out using Origin Pro 2017 and Excel 2016. Excel 2016 was used to process the experimental data, and Origin Pro 2017 was used to organize the data into graphs. $\mathrm{P}<0.05$ was considered to be significant.

\section{Results and discussion}

\subsection{Optimization of ultrasound-assisted extraction}

In recent years, UAE of compounds has been applied to a wide range of applications.

UAE improves the mass transfer of the extraction process due to the cavitation effect in the material. When cavitation bubbles are generated and subsequently collapse, the 
cell walls of the material are destroyed and this promotes the release of solutes ${ }^{36}$. In this study, impact of four different factors (relative position of two ultrasound probes, solvent to material ratio, ultrasound time and concentration of ethanol) on triterpenoids yield was studied.

\subsubsection{Effect of relative position of two ultrasound probes}

As shown in Figure 1(a), the effects of different probe positions were compared in dual frequency; one is parallel and the other is vertical. The ultrasound power of both probes was $180 \mathrm{~W}$ operating at two different frequencies; $15 \mathrm{kHz}$ and $20 \mathrm{kHz}$. Ultrasound treatment was carried out for 10 minutes and the solvent to material ratio was kept at 1:50. $95 \% \mathrm{v} / \mathrm{v}$ ethanol was used and both ultrasonic probes were $4 \mathrm{~cm}$ from the extract. When the probes were kept in parallel, the yield of triterpenoids was $0.59 \pm 0.01 \%$. However, when the relative positions of the probes were vertical, the extraction rate increased by $47 \%$; yielding $0.87 \pm 0.04 \%$ of extract. Based on these results, the two ultrasound probes were kept in vertical position for the following experiments.

\subsubsection{Effect of solvent to material ratio}

It is vital to optimize the solvent to material ratio as if it is too low, it will discourage mass transfer rate ${ }^{37}$. On the other hand, a high solvent to material ratio can induce prolonged distance of diffusion towards the interior substance ${ }^{38}$. This subsequently can interfere with its dissolution rate. Therefore, the optimal ratio needs to be established. The results were shown in Figure 2(a). The concentration of ethanol was 95\% v/v. The ultrasound time was $10 \mathrm{~min}$. Both probes had ultrasound power of $180 \mathrm{w}$. The 
frequency was $15 \mathrm{KHz}$ and the other was $20 \mathrm{KHz}$. The relative positions of the two ultrasound probes were vertical. Both ultrasonic probes are $4 \mathrm{~cm}$ away from the extract. From the Figure 2(a), it can be observed that when the solvent to material ratio was modified from 20:1 to 50:1 mL/g, the yield of triterpenoids improved gradually. Once the ratio was $60: 1$, the yield was constant; with no change upon using more solvent. Considering solvent savings, a ratio of $50: 1 \mathrm{~mL} / \mathrm{g}$ was selected as the optimum solvent to material proportion.

\subsubsection{Effect of ultrasound time}

The time of ultrasound treatment is also critical in this study. Here, the period of ultrasound application was varied between 1 and 30 minutes whilst all other factors were kept constant: Solvent to material ratio $=50: 1$, concentration of ethanol $=95 \%$ $\mathrm{v} / \mathrm{v}$, ultrasound power of both probes: $180 \mathrm{w}$ and frequencies of $15 \mathrm{KHz}$ and $20 \mathrm{KHz}$.

Figure 2(b) demonstrates that when increasing the ultrasound time from 1 minute to 10 minutes, the extraction rate gradually increased. When using an ultrasound treatment time of 10 minutes, the highest yield of triterpenoids was achieved $(1.38 \pm 0.04 \%)$. Prolonging the treatment time beyond 10 minutes caused the yield to decrease; indicating possible degradation of triterpenoids. There was a similar phenomenon when extracting quercetin in Nasturtium officinale ${ }^{39}$. As a result of this, an ultrasound treatment of 10 minutes was selected as the optimal time.

\subsubsection{Effect of concentration of ethanol}


The concentration of the solvent used in the extraction process may affect the extraction rate or the yield and therefore needs to be studied. Ethanol was chosen as the solvent in this study based on the principle of similar compatibility and that triterpenoids are polar compounds ${ }^{40}$. Figure 2(c) shows that the concentration of the solvent does have an effect on triterpenoid yield. When ethanol concentration increased from 70 to $95 \% \mathrm{v} / \mathrm{v}$, the yield of the extract increased from $0.52 \pm 0.034 \%$ to $1.43 \pm 0.0084 \%$. These results can be described based on the "like dissolves like" theory: as the concentration of ethanol increased, the polarity of the solution also increased in turn increasing the extraction rate ${ }^{41}$. A maximum triterpenoid yield was achieved when using an ethanol concentration of $95 \% \mathrm{v} / \mathrm{v}$ and this value was selected for all subsequent experiments.

\subsection{FTIR}

In order to study the effects of the relative position of dual-frequency ultrasound extraction on the structure of triterpenoids FTIR analysis was carried out. The resulting spectra is shown in Figure 3. Oleanolic acid was used as a reference and had several distinctive peaks. The peak at $3459 \mathrm{~cm}^{-1}$ corresponds to $\mathrm{OH}$ stretching bond, while the peak at $2293.98 \mathrm{~cm}^{-1}$ was as a result of a $\mathrm{CH}$-(aliphatic) asymmetric stretching vibration bond. Peaks at $2859.38 \mathrm{~cm}^{-1}$ and $1689.31 \mathrm{~cm}^{-1}$ were due to $\mathrm{CH}_{3^{-}}$(aliphatic) symmetric stretching and $\mathrm{CO}$ stretching vibration bonds, respectively. The deformation for $\mathrm{CH}$ is seen as a peak at $1161.1 \mathrm{~cm}^{-1}$, and the asymmetric $\mathrm{CH} 3$-deformation peak can be observed at $1461.66 \mathrm{~cm}^{-1} 42$. 
Here, single-frequency ultrasonic extraction, dual-frequency vertical ultrasonic extraction and dual-frequency parallel ultrasonic extraction. When compared to the reference, similar peaks can be observed for all three extraction methods. Peaks at $2859.38 \mathrm{~cm}^{-1}, 1868.31 \mathrm{~cm}^{-1}$ and $1461.66 \mathrm{~cm}^{-1}$ are consistent with oleanolic acid. One thing to note here the extracted triterpenoid content. As this is quite low, some peaks may not be identifiable due to weak transmission. Regardless, the FTIR results confirm that none of three extraction methods compromised the structure of the extracted triterpenoids.

\subsection{BBD for optimization of effective parameters}

The Box-Behnken Design (BBD) model was used to study any interactions between variables: solvent to solid ratio (A), ultrasound treatment time (B) and ethanol concentration (C). The optimal experimental conditions were determined from the BBD model. The second order quadratic model was expressed by the following equation. $\mathrm{Y}=1.21+0.079 \mathrm{~A}+8.750 \times 10^{-3} \mathrm{~B}-0.022 \mathrm{C}+2.500 \times 10^{-3} \mathrm{AB}-0.025 \mathrm{AC}+0.010 \mathrm{BC}-$ $0.078 \mathrm{~A}^{2}-0.058 \mathrm{~B}^{2}-0.14 \mathrm{C}^{2}$

To verify the significance and adequacy of the model, an analysis of variance (ANOVA) was performed (Table 3). A high F-value (F model=19.19) and a low probability value $(\mathrm{P}$ model $=0.0004)$ indicated that the model was significant. The lack of fit term was not significant ( $\mathrm{p}$ value 0.2531 ), which suggested the model equation was sufficient to predict the yield of ultrasound extraction when the relative probe position was vertical. The high $\mathrm{R}^{2}$ valve $(0.9610)$ implied that the experimental and predicted values 
correlated highly. This means that $96.1 \%$ of the total variation in the response could be explained by the model ${ }^{43}$.

Figure 4 shows the 3D and 2D surface plots between every two independent variables. Figure 4(a) and (d) show three-dimensional and two-dimensional response surface plots for interactive effects of solvent to solid ratio and ultrasound time on response values at fixed ethanol concentration. When the ultrasound treatment time was fixed, the yield of triterpenoids rapidly increased with the increase of the solvent to material ratio. After reaching the optimal maximum, the yield slowly decreased. A similar trend was observed when fixing the solvent to solid ratio. From Figure 4(b) and (e), it can see that the effect of ethanol concentration on the yield of triterpenoids is not obvious when compared with the ratio of liquid to liquid. As shown in Figure 4(c) and (f), compared with the ultrasound time, the effect of ethanol concentration on the yield of triterpenoids is more significant.

A variety of factors can be assessed using the Box-Behnken Design in order to select the suitable process parameters in practice ${ }^{44}$. To assess the optimum conditions for the maximum yield of triterpenoids, three variables (solvent to solid ratio, ultrasound time and ethanol concentration) were set to the studied range. The Box-Behnken Design and analytical software suggested the optimal process conditions of ultrasound-assisted extraction of triterpenoids were as follows: a solvent to solid ratio of 55:28, 10.38 minutes of ultrasound time and $94 \% \mathrm{v} / \mathrm{v}$ of ethanol concentration. The yield of triterpenoids under such conditions was theoretically predicted to be $1.23 \%$. The 
experiments at the predicted optimum conditions were carried out in triplicate. The average value was $1.15 \%$, confirming the validity and adequacy of the model.

\subsection{Triterpenoid profiles by HPLC-Q-TOF-MS}

Representative HPLC chromatographs of triterpenoids extract obtained at optimized parameters are shown in Figure 5. Triterpenoid extract contained 10 major compounds. As shown in Figure 5(a), there was ganocochlearin B (peak 1), ganoderic acid I (peak 2), lucidenic acid D (peak 3), ganoderenic acid D (peak 4), ganodernoid C (peak 5), ganoderic acid DM (peak 6) and ganodermic acid TQ (peak 7). In Figure 5(b), we could see ganoderenic acid D (peak 1), ganoderiol I (peak 2) and ganoderic acid C2 (peak 3).

These peaks show mainly the ganoderma triterpenoids in ethanol. Figure 6 shows the chemical structures of the components identified in ethanol. From these results, it was apparent that tetracyclic triterpenoids were the main compounds present in the ethanol extracts.

\subsection{The radical-scavenging activity}

The radical scavenging activity of the extracted compounds was evaluated by comparing the percentage inhibition of DPPH radicals between samples and the control. As seen in Figure 7, the scavenging activities increased with the increase in triterpenoids concentration. The percentage of scavenging was only $34.52 \pm 1.41 \%$ when using a concentration of $100 \mu \mathrm{g} / \mathrm{mL}$ of triterpenoids. This increased and reached a maximum $(61.09 \pm 1.38 \%)$ when using a triterpenoid concentration of $600 \mu \mathrm{g} / \mathrm{mL}$. 
These results show that the extracted compound exhibited mild radical scavenging activity.

\subsection{Antimicrobial activity}

The antimicrobial activity of the extracted triterpenoids was assessed using two bacteria; Escherichia coli and Staphylococcus aureus and the resulting data is shown in Figure 8. The control group was void of triterpenoids. It is clear to see that the diameter of the zone of inhibition increased as the concentration of triterpenoids increased. Figure 8(a) showed that when the volumes of triterpenoids were $2 \mu \mathrm{L}, 4 \mu \mathrm{L}, 6 \mu \mathrm{L}$, and $8 \mu \mathrm{L}$, the average inhibition zone diameter for E. coli were 10.34, 10.36, 11.04 and $11.69 \mathrm{~mm}$, respectively. Similarly, Figure 8(b) shows the antibacterial activity of triterpenoids against $S$. aureus at different volumes. These studies revealed that the mean zones of inhibition were $10.65,11.06,11.74$ and $11.83 \mathrm{~mm}$ for volumes of $2 \mu \mathrm{L}, 4 \mu \mathrm{L}, 6 \mu \mathrm{L}$, and $8 \mu \mathrm{L}$, respectively. As can be seen in both Figure 8(a) and 8(b), when the volume of the triterpenoids was 6 and $8 \mu \mathrm{L}$, the diameter of the inhibition zone was significant (p $<0.05)$. E. coli is a Gram-negative bacterium and S. aureus is a model Gram-positive bacterium. To date, most antibacterial medicinal plants are active against Gram-positive bacteria but very few against Gram-negative bacteria due to the difference in susceptibility between them ${ }^{45}$. From these experimental results, triterpenoids have demonstrated broad-spectrum antibacterial properties and can therefore be used to develop new antibacterial drugs.

\subsection{Cell viability assays}


Figure 9 highlights the effect of modifying triterpenoid concentration on cell viability of L929. Concentrations ranging from 10 to $800 \mu \mathrm{g} / \mathrm{mL}$ were studied. Figure 9(a) shows that increasing triterpenoid concentration from 10 to $200 \mu \mathrm{g} / \mathrm{mL}$, cell viability also increased gradually; from $107.67 \%$ to $122.13 \%$. This suggested that triterpenoids (concentration less than or equal to $200 \mu \mathrm{g} / \mathrm{mL}$ ) had adequate biocompatibility with L929 cells. However, surpassing this optimal concentration saw cell viability decrease slowly, falling to $82.49 \%$ when assessing triterpenoid concentration of $800 \mu \mathrm{g} / \mathrm{mL}$. This illustrates that the triterpenoids caused weak toxicity to L929 cells in high concentrations.

In order to observe the effect of triterpenoids on L929 cell morphology, a fluorescent staining experiment was performed (Figure 9(b)). From the figure, it can be seen that the cells show a full oval or fusiform shape. When compared to the control, there is no significant difference in cell morphology following treatment with the extracted triterpenoids. Increasing extract concentration from 10 to $200 \mu \mathrm{g} / \mathrm{mL}$ resulted a significantly higher number of cells with smaller cell spacing, indicating good biocompatibility. Increasing the triterpenoid concentration to $800 \mu \mathrm{g} / \mathrm{mL}$ resulted in a reduced number of cells with a small number of round cells being present; further highlighting the toxicity of triterpenoids to cells at high concentrations.

\subsection{Anticancer activity (Hela)}

Among various cancers, cervical cancer is placed at second most common malignant tumor in women worldwide ${ }^{46}$. As described by the other authors ${ }^{47}$, G. lucidum 
triterpenoid extract induces apoptosis in human colon carcinoma cells. Few studies have reported the effects of G. lucidum triterpenoids on cervical cancer in humans. In this study, the effect of different concentrations of triterpenoids on cell viability of Human Cervical Carcinoma Hela cells was evaluated. Extract concentrations ranged from 10 to $800 \mu \mathrm{g} / \mathrm{mL}$. From Figure 10(a), it is clear to see that when the concentration of triterpenoids was low (i.e. from 10 to $100 \mu \mathrm{g} / \mathrm{mL}$ ), cell toxicity was also weak and the cell survival rate increased. Cell viability was $99.98 \%$ when using a triterpenoid concentration of $100 \mu \mathrm{g} / \mathrm{mL}$. However, cell viability decreased with increasing concentrations ( $\geq 200 \mu \mathrm{g} / \mathrm{mL}$ ) of triterpenoids. At a concentration of $800 \mu \mathrm{g} / \mathrm{mL}$, the cell survival rate was only $51.66 \%$, demonstrating the potential anticancer properties of the extracted triterpenoids.

Figure 10(b) presents fluorescent staining images under the effect of triterpenoids on L929 cell morphology. The morphology of cells treated by triterpenoids showed no significant difference to the control. The cells presented irregular fusiform morphology. When the concentration of triterpenoids was $100 \mu \mathrm{g} / \mathrm{mL}$, there was no significant difference compared with the control but when assessing a concentration $800 \mu \mathrm{g} / \mathrm{mL}$, the number of cells was significantly reduced and round cells were present; mimicking the results found with the cell viability results.

When comparing the effects of triterpenoids on the viability of Hela and L929 cells, it can be concluded that when a low concentration of triterpenoids is used, it can promote normal cell growth and with weak inhibitory effects on Hela cells. When the 
concentration of triterpenoids was high, it was weakly toxic to normal cells, but it has a significant inhibitory effect on Hela cells. Therefore, it's a promising role as an effective chemotherapeutic agent against human cervical cancer.

\section{Conclusion}

Here, triterpenoids were successfully extracted from GLSP by using a dual ultrasound transducers-assisted method. RSM was used to optimize three different factors related to extraction; presenting the following optimal values: solvent to solid ratio: $55: 28$, ultrasound treatment time: 10.38 and ethanol concentration: 94\% v/v. In addition, 9 different compounds found in triterpenoids were confirmed by HPLC-Q-TOF-MS. The extracted triterpenoids demonstrated the inhibition of DPPH radicals, reaching a maximum $(61.09 \pm 1.38 \%)$ at concentration of $600 \mu \mathrm{g} / \mathrm{mL}$. In addition to this, the triterpenoids extract showed broad-spectrum antibacterial properties $(\mathrm{p}<0.05)$ on $S$. aureus and E. coli alongside good biocompatibility with potential in antibacterial and anticancer applications.

\section{Acknowledgements}

This work was financially supported by the National Nature Science Foundation of China (No.81301304) and the Key Technologies R\&D Program of Zhejiang Province (2015C02035). 


\section{Reference}

1. Dudra, A.; Strugała, P.; Pyrkosz Biardzka, K.; Sroka, Z.; Gabrielska, J., A Study on Biological Activity of the Polyphenol Fraction from Fruits of Rosa Rugosa Thunb. Journal of Food Biochemistry 2016, 40, (4), 411-419.

2. Eshun, K.; He, Q., Aloe Vera: A Valuable Ingredient for the Food, Pharmaceutical and Cosmetic Industries-A Review. Critical Reviews in Food Science and Nutrition 2004, 44, (2), 91-96.

3. Johanningsmeier, S. D.; Harris, G. K., Pomegranate as a Functional Food and Nutraceutical Source. Annual Review of Food Science and Technology 2011, 2, (1), 181-201.

4. Hosseini, A.; Ghorbani, A., Cancer therapy with phytochemicals: evidence from clinical studies. Avicenna journal of phytomedicine 2015, 5, (2), 84-97.

5. Jin, M.; Zhang, H.; Wang, J.; Shao, D.; Yang, H.; Huang, Q.; Shi, J.; Xu, C.; Zhao, K., Response of intestinal metabolome to polysaccharides from mycelia of Ganoderma lucidum. International Journal of Biological Macromolecules 2019, 122 , 723-731.

6. Shen, J.; Park, H. S.; Xia, Y. M.; Kim, G. S.; Cui, S. W., The polysaccharides from fermented Ganoderma lucidum mycelia induced miRNAs regulation in suppressed HepG2 cells. Carbohydrate Polymers 2014, 103, 319-324.

7. Cuong, V. T.; Chen, W.; Shi, J.; Zhang, M.; Yang, H.; Wang, N.; Yang, S.; Li, J.; Yang, P.; Fei, J., The anti-oxidation and anti-aging effects of Ganoderma lucidum in Caenorhabditis elegans. Experimental Gerontology 2019, 117, 99-105.

8. Zhao, C.; Zhang, C.; Xing, Z.; Ahmad, Z.; Li, J. S.; Chang, M. W., Pharmacological effects of natural Ganoderma and its extracts on neurological diseases: A comprehensive review. International Journal of Biological Macromolecules 2019, 121, 1160-1178.

9. Fan, L.; Wang, Y.; Zhao, M.; Song, J.; Wang, J.; Jin, Z., Magnetic Ganoderma lucidum spore microspheres: A novel material to immobilize CotA multicopper oxidase for dye decolorization. Journal of Hazardous Materials 2016, 313, 122-129. 10. Ge, F. H.; Duan, M. H.; Li, J.; Shi, Q. L., Ganoderin A, a novel 9,11-secosterol from Ganoderma lucidum spores oil. Journal of Asian Natural Products Research 2017, 19, (12), 1252-1257.

11. Ho, Y. W.; Yeung, J. S. L.; Chiu, P. K. Y.; Tang, W. M.; Lin, Z. B.; Man, R. Y. K.; Lau, C. S., Ganoderma lucidum polysaccharide peptide reduced the production of proinflammatory cytokines in activated rheumatoid synovial fibroblast. Molecular and Cellular Biochemistry 2007, 301, (1), 173-179.

12. Wang, C.; Shi, S.; Chen, Q.; Lin, S.; Wang, R.; Wang, S.; Chen, C., Antitumor and Immunomodulatory Activities of Ganoderma lucidum Polysaccharides in Glioma-Bearing Rats. Integrative Cancer Therapies 2018, 17, (3), 674-683.

13. Li, L. F.; Liu, H. B.; Zhang, Q. W.; Li, Z. P.; Wong, T. L.; Fung, H. Y.; Zhang, J. X.; Bai, S. P.; Lu, A. P.; Han, Q. B., Comprehensive comparison of polysaccharides 
from Ganoderma lucidum and G. sinense: chemical, antitumor, immunomodulating and gut-microbiota modulatory properties. Scientific Reports 2018, 8, (1), 6172. 14. Zhu, L.-F.; Yao, Z.-C.; Ahmad, Z.; Li, J.-S.; Chang, M.-W., Synthesis and Evaluation of Herbal Chitosan from Ganoderma Lucidum Spore Powder for Biomedical Applications. Scientific Reports 2018, 8, (1), 14608.

15. Zhu, L. F.; Chen, X.; Ahmad, Z.; Li, J. S.; Chang, M. W., Engineering of Ganoderma lucidum polysaccharide loaded polyvinyl alcohol nanofibers for biopharmaceutical delivery. Journal of Drug Delivery Science and Technology 2019, 50, 208-216.

16. Lin, Z. B.; Wang, P. Y., The pharmacological study of Ganoderma spores and their active components. Beijing Da Xue Xue Bao Yi Xue Ban 2006, 38, (5), 541-547. 17. Su, J.; Su, L.; Li, D.; Shuai, O.; Zhang, Y.; Liang, H.; Jiao, C.; Xu, Z.; Lai, Y.; Xie, Y., Antitumor Activity of Extract From the Sporoderm-Breaking Spore of Ganoderma lucidum: Restoration on Exhausted Cytotoxic T Cell With Gut Microbiota Remodeling. Frontiers in Immunology 2018, 9, 1765.

18. Li, H. J.; He, Y. L.; Zhang, D. H.; Yue, T. H.; Jiang, L. X.; Li, N.; Xu, J. W., Enhancement of ganoderic acid production by constitutively expressing Vitreoscilla hemoglobin gene in Ganoderma lucidum. Journal of Biotechnology 2016, 227, 35-40. 19. Azmir, J.; Zaidul, I. S. M.; Rahman, M. M.; Sharif, K. M.; Mohamed, A.; Sahena, F.; Jahurul, M. H. A.; Ghafoor, K.; Norulaini, N. A. N.; Omar, A. K. M., Techniques for extraction of bioactive compounds from plant materials: A review. Journal of Food Engineering 2013, 117, (4), 426-436.

20. Abid, M.; Jabbar, S.; Wu, T.; Hashim, M. M.; Hu, B.; Lei, S.; Zeng, X., Sonication enhances polyphenolic compounds, sugars, carotenoids and mineral elements of apple juice. Ultrasonics Sonochemistry 2014, 21, (1), 93-97.

21. Zhao, D.; Chang, M.; Li, J.; Suen, W.; Huang, J., Investigation of Ice-Assisted Sonication on the Microstructure and Chemical Quality of Ganoderma lucidum Spores. Journal of food science 2014, 79, (11), E2253-E2265.

22. Bimakr, M.; Ganjloo, A.; Zarringhalami, S.; Ansarian, E., Ultrasound-assisted extraction of bioactive compounds from Malva sylvestris leaves and its comparison with agitated bed extraction technique. Food Sci Biotechno 2017, 26, (6), 1481-1490. 23. Zhu, L. F.; Li, J. S.; Mai, J.; Chang, M. W., Ultrasound-assisted synthesis of chitosan from fungal precursors for biomedical applications. Chemical Engineering Journal 2019, 357, 498-507.

24. Wang, C.; Wang, H.; Gu, G., Ultrasound-assisted xanthation of cellulose from lignocellulosic biomass optimized by response surface methodology for $\mathrm{Pb}$ (II) sorption. Carbohydrate Polymers 2018, 182, 21-28.

25. Chen, W.; Wang, W. P.; Zhang, H. S.; Huang, Q., Optimization of ultrasonicassisted extraction of water-soluble polysaccharides from Boletus edulis mycelia using response surface methodology. Carbohydrate Polymers 2012, 87, (1), 614-619. 
26. Jiang, H. L.; Yang, J. L.; Shi, Y. P., Optimization of ultrasonic cell grinder extraction of anthocyanins from blueberry using response surface methodology.

Ultrasonics Sonochemistry 2017, 34, 325-331.

27. Živković, J.; Šavikin, K.; Janković, T.; Ćujić, N.; Menković, N., Optimization of ultrasound-assisted extraction of polyphenolic compounds from pomegranate peel using response surface methodology. Separation and Purification Technology 2018, 194, 40-47.

28. Quanhong, L.; Caili, F., Application of response surface methodology for extraction optimization of germinant pumpkin seeds protein. Food Chemistry 2005, 92, (4), 701-706.

29. Pandey, D. K.; Kaur, P., Optimization of extraction parameters of pentacyclic triterpenoids from Swertia chirata stem using response surface methodology. 3 Biotech 2018, 8, (3), 152.

30. Wu, S.; Li, J.; Mai, J.; Chang, M., Three-dimensional electrohydrodynamic printing and spinning of flexible composite structures for oral multidrug forms. $A C S$ applied materials \& interfaces 2018, 10, (29), 24876-24885.

31. Uysal, S.; Aktumsek, A., A phytochemical study on Potentilla anatolica: An endemic Turkish plant. Industrial Crops and Products 2015, 76, 1001-1007.

32. Mot, C. A.; Copolovici, D.; Madosa, E.; Mot, G.; Copolovici, L., The chemical composition and pharmaceutical usage of Hawthorn (Crataegus monogyna L.) extracts. Journal of Biotechnology 2016, 231, S59.

33. Carrasco, V.; Pinto, L. A.; Cordeiro, K. W.; Cardoso, C. A. L.; Freitas, K. D. C., Antiulcer activities of the hydroethanolic extract of Sedum dendroideum Moc et Sessé ex DC. (balsam). Journal of Ethnopharmacology 2014, 158, 345-351.

34. Wasihun, A. G.; Wlekidan, L. N.; Gebremariam, S. A.; Welderufael, A. L.; Muthupandian, S.; Haile, T. D.; Dejene, T. A., Diagnosis and Treatment of Typhoid Fever and Associated Prevailing Drug Resistance in Northern Ethiopia. International Journal of Infectious Diseases 2015, 35, 96-102.

35. Zhong, Y.; Chen, X.; Peng, H.; Ding, Z.; Yan, Y., Developing novel Cazeolite/poly(amino acid) composites with hemostatic activity for bone substitute applications. Journal of Biomaterials Science, Polymer Edition 2018, 29, (16), 19942010.

36. Toma, M.; Vinatoru, M.; Paniwnyk, L.; Mason, T. J., Investigation of the effects of ultrasound on vegetal tissues during solvent extraction. Ultrasonics Sonochemistry 2001, 8, (2), 137-142.

37. Mandal, V.; Mandal, S. C., Design and performance evaluation of a microwave based low carbon yielding extraction technique for naturally occurring bioactive triterpenoid: Oleanolic acid. Biochemical Engineering Journal 2010, 50, (1), 63-70. 38. Ying, Z.; Han, X.; Li, J., Ultrasound-assisted extraction of polysaccharides from mulberry leaves. Food Chemistry 2011, 127, (3), 1273-1279.

39. Asfaram, A.; Ghaedi, M.; Javadian, H.; Goudarzi, A., Cu- and S- @ $\mathrm{SnO}_{2}$ nanoparticles loaded on activated carbon for efficient ultrasound assisted dispersive 
$\mu$ SPE-spectrophotometric detection of quercetin in Nasturtium officinale extract and fruit juice samples: CCD-RSM design. Ultrasonics Sonochemistry 2018, 47, 1-9. 40. Vinh, L. B.; Jang, H. J.; Phong, N. V.; Cho, K.; Park, S. S.; Kang, J. S.; Kim, Y. H.; Yang, S. Y., Isolation, structural elucidation, and insights into the antiinflammatory effects of triterpene saponins from the leaves of Stauntonia hexaphylla. Bioorganic \& Medicinal Chemistry Letters 2019, 29, (8), 965-969.

41. Carciochi, R. A.; Manrique, G. D.; Dimitrov, K., Optimization of antioxidant phenolic compounds extraction from quinoa (Chenopodium quinoa) seeds. Journal of Food Science and Technology 2015, 52, (7), 4396-4404.

42. Ghosh, S.; Kar, N.; Bera, T., Oleanolic acid loaded poly lactic co- glycolic acidvitamin E TPGS nanoparticles for the treatment of Leishmania donovani infected visceral leishmaniasis. International Journal of Biological Macromolecules 2016, 93, 961-970.

43. Asfaram, A.; Ghaedi, M.; Dashtian, K.; Ghezelbash, G. R., Preparation and Characterization of $\mathrm{Mn}_{0.4} \mathrm{Zn}_{0.6} \mathrm{Fe}_{2} \mathrm{O}_{4}$ Nanoparticles Supported on Dead Cells of Yarrowia lipolytica as a Novel and Efficient Adsorbent/Biosorbent Composite for the Removal of Azo Food Dyes: Central Composite Design Optimization Study. ACS Sustainable Chemistry \& Engineering 2018, 6, (4), 4549-4563.

44. Sakr, M.; Hanafi, R.; Fouad, M.; Al-Easa, H.; El-Moghazy, S., Design and optimization of a luminescent Samarium complex of isoprenaline: A chemometric approach based on Factorial design and Box-Behnken response surface methodology. Spectrochimica Acta Part A: Molecular and Biomolecular Spectroscopy 2019, 208, 114-123.

45. Meng, J. C.; Zhu, Q. X.; Tan, R. X., New Antimicrobial Mono- and Sesquiterpenes from Soroseris hookeriana Subsp. erysimoides. Planta Med 2000, 66, (06), 541-544.

46. Zhang, F.; Zhang, J. G.; Qu, J.; Zhang, Q.; Prasad, C.; Wei, Z. J., Assessment of anti-cancerous potential of 6-gingerol (Tongling White Ginger) and its synergy with drugs on human cervical adenocarcinoma cells. Food and Chemical Toxicology 2017, 109, 910-922.

47. Ruan, W.; Popovich, D. G., Ganoderma lucidum triterpenoid extract induces apoptosis in human colon carcinoma cells (Caco-2). Biomedicine \& Preventive Nutrition 2012, 2, (3), 203-209. 


\section{Tables}

\section{Table 1}

Coded variable levels and outcomes for variables.

\begin{tabular}{lllll}
\hline Variables & \multicolumn{4}{c}{ Coded levels of variables } \\
& & -1 & 0 & 1 \\
\hline Solvent to solid ratio (mL/g) & A & 40 & 50 & 60 \\
Ultrasound time (min) & B & 5 & 10 & 15 \\
Ethanol concentration (\%) & C & 90 & 95 & 100 \\
\hline
\end{tabular}


Table 2

Experimental design and results for the Box-Behnken Model.

\begin{tabular}{|c|c|c|c|c|}
\hline \multirow[t]{2}{*}{ Test run no. } & \multicolumn{3}{|c|}{ Coded levels of variables } & \multirow[t]{2}{*}{ Yield of triterpenoids $(\%)$} \\
\hline & A & $\mathrm{B}$ & $\mathrm{C}$ & \\
\hline 1 & 1 & 1 & 0 & 1.17 \\
\hline 2 & 1 & -1 & 0 & 1.15 \\
\hline 3 & -1 & 1 & 0 & 0.99 \\
\hline 4 & -1 & -1 & 0 & 0.98 \\
\hline 5 & 1 & 0 & 1 & 0.99 \\
\hline 6 & 1 & 0 & -1 & 1.13 \\
\hline 7 & -1 & 0 & 1 & 0.90 \\
\hline 8 & -1 & 0 & -1 & 0.94 \\
\hline 9 & 0 & -1 & 1 & 0.99 \\
\hline 10 & 0 & -1 & -1 & 1.01 \\
\hline 11 & 0 & 1 & 1 & 1.03 \\
\hline 12 & 0 & 1 & -1 & 1.01 \\
\hline 13 & 0 & 0 & 0 & 1.25 \\
\hline 14 & 0 & 0 & 0 & 1.20 \\
\hline 15 & 0 & 0 & 0 & 1.18 \\
\hline 16 & 0 & 0 & 0 & 1.22 \\
\hline 17 & 0 & 0 & 0 & 1.19 \\
\hline
\end{tabular}




\section{Table 3}

Variance analysis of Ganoderma lucidum triterpenoid yield.

\begin{tabular}{|c|c|c|c|c|c|c|}
\hline Source & $\begin{array}{l}\text { Sum of } \\
\text { Squares }\end{array}$ & $\mathrm{df}$ & $\begin{array}{l}\text { Mean } \\
\text { Square }\end{array}$ & $\begin{array}{c}\mathrm{F} \\
\text { Value }\end{array}$ & p-value & Significant \\
\hline Model & 0.19 & 9 & 0.021 & 19.19 & 0.0004 & Significant \\
\hline $\begin{array}{c}\text { A- solvent } \\
\text { to solid }\end{array}$ & 0.50 & 1 & 0.050 & 44.78 & 0.0003 & \\
\hline $\begin{array}{c}\text { B- } \\
\text { ultrasound }\end{array}$ & $6.125 \mathrm{E}-004$ & 1 & $6.125 \mathrm{E}-004$ & 0.55 & 0.4814 & \\
\hline $\begin{array}{l}\text { C- ethanol } \\
\text { concentratio }\end{array}$ & 4.050E-003 & 1 & 4.050E-003 & 3.66 & 0.0975 & \\
\hline $\mathrm{AB}$ & $2.500 \mathrm{E}-005$ & 1 & $2.500 \mathrm{E}-005$ & 0.023 & 0.8848 & \\
\hline $\mathrm{AC}$ & $2.500 \mathrm{E}-003$ & 1 & $2.500 \mathrm{E}-003$ & 2.26 & 0.1767 & \\
\hline $\mathrm{BC}$ & 4.000E-004 & 1 & 4.000E-004 & 0.36 & 0.5669 & \\
\hline $\mathrm{A}^{\wedge} 2$ & 0.025 & 1 & 0.025 & 22.97 & 0.0020 & \\
\hline $\mathrm{B}^{\wedge} 2$ & 0.014 & 1 & 0.014 & 12.68 & 0.0092 & \\
\hline $\mathrm{C}^{\wedge} 2$ & 0.083 & 1 & 0.083 & 74.76 & $<$ & \\
\hline Residual & 7.755E-003 & 7 & $1.108 \mathrm{E}-003$ & & 0.0001 & \\
\hline Lack of Fit & 4.675E-003 & 3 & $1.558 \mathrm{E}-003$ & 2.02 & 0.2531 & $\begin{array}{c}\text { Not } \\
\text { significant }\end{array}$ \\
\hline Pure Error & $3.080 \mathrm{E}-003$ & 4 & 7.700E-004 & & & \\
\hline Cor Total & 0.20 & 16 & & & & \\
\hline
\end{tabular}




\section{Figures Caption}

Figure 1 (a) Experimental setup of dual ultrasound extraction and (b) the standard absorption curve of oleanolic acid.

Figure 2 The effect of ultrasound extraction variables on triterpenoid yield. (a) Effect of solvent to material ratio, $1 \mathrm{~g}$ GLSP extracted with 95\% ethanol for $10 \mathrm{~min}$. (b) Effect of ultrasound time, $1 \mathrm{~g}$ GLSP extracted with $50 \mathrm{~mL}(95 \%)$ ethanol. (c) Effect of concentration of ethanol. $1 \mathrm{~g}$ GLSP extracted with $50 \mathrm{~mL}$ ethanol for $10 \mathrm{~min}$. Each measurement was carried out in triplicate. Each value represents a mean $\pm \operatorname{SD}(n=3)$.

Figure 3 FTIR spectra of the sample. $\mathrm{U}_{2}$ : Single frequency ultrasound extraction; U1 $\perp \mathrm{U} 2$ : Dual frequency ultrasound extraction and the position of the two probes was vertical; $\mathrm{U}_{1} \| \mathrm{U}_{2} *$ : Dual frequency ultrasound extraction and the position of the two probes was parallel.

Figure 4 Three-dimensional and two-dimensional response surface contour plots showing the experiment factors and their mutual interactions on triterpenoids yield.

Figure 5 Results of detection of triterpenoid extracts by fast high performance liquidphase quadrupole time-of-flight (Q-TOF) mass spectrometry. (a) 1. ganocochlearin B 2. ganoderic acid I 3. lucidenic acid D 4. ganoderenic acid D 5. ganodernoid C 6 . ganoderic acid DM 7. ganodermic acid TQ. (b) 1. ganoderenic acid D 2. ganoderiol I 3. ganoderic acid $\mathrm{C} 2$.

Figure 6 The structural formula of the chemical composition shown in Figure 3.

Figure 7 DPPH radical-scavenging activities of triterpenoids from GLSP. 
Figure 8 Antibacterial activity of different volumes of triterpenoids against E. coli (a) and $S$. aureus (b). ${ }^{*} \mathrm{p}<0.05$, significantly different from the control.

Figure 9 (a) Cell viability of L929 cells with different concentrations of triterpenoids $(10,50,100,200,400,600,800 \mu \mathrm{g} / \mathrm{mL})$; (b) Fluorescent images of L929 cell morphology. a1- f1 were bright-field image and a2-f2 were merged image of cell morphology. a1, a2 were the control; b1, b2: the concentration of triterpenoids was $10 \mu \mathrm{g} / \mathrm{mL}$; $\mathrm{c} 1$, c2: the concentration of triterpenoids was $50 \mu \mathrm{g} / \mathrm{mL}$; d1, d2: the concentration of triterpenoids was $100 \mu \mathrm{g} / \mathrm{mL}$; e1, e2: the concentration of triterpenoids was $200 \mu \mathrm{g} / \mathrm{mL}$; f1, f2: the concentration of triterpenoids was $800 \mu \mathrm{g} / \mathrm{mL}$.

Figure 10 (a) Effect of triterpenoid concentration $(10,50,100,200,400,600,800 \mu \mathrm{g} / \mathrm{mL})$ on the cell viability of Hela cells by the CCK-8 assay. (b) Fluorescent images of Hela cell morphology. a1-c1 were bright-field image and a2-c2 were merged image of cell morphology. a1, a 2 were the control; b1, b2: the concentration of triterpenoids was 100 $\mu \mathrm{g} / \mathrm{mL}$; 1 , c 2 : the concentration of triterpenoids was $800 \mu \mathrm{g} / \mathrm{mL}$. 
(a)
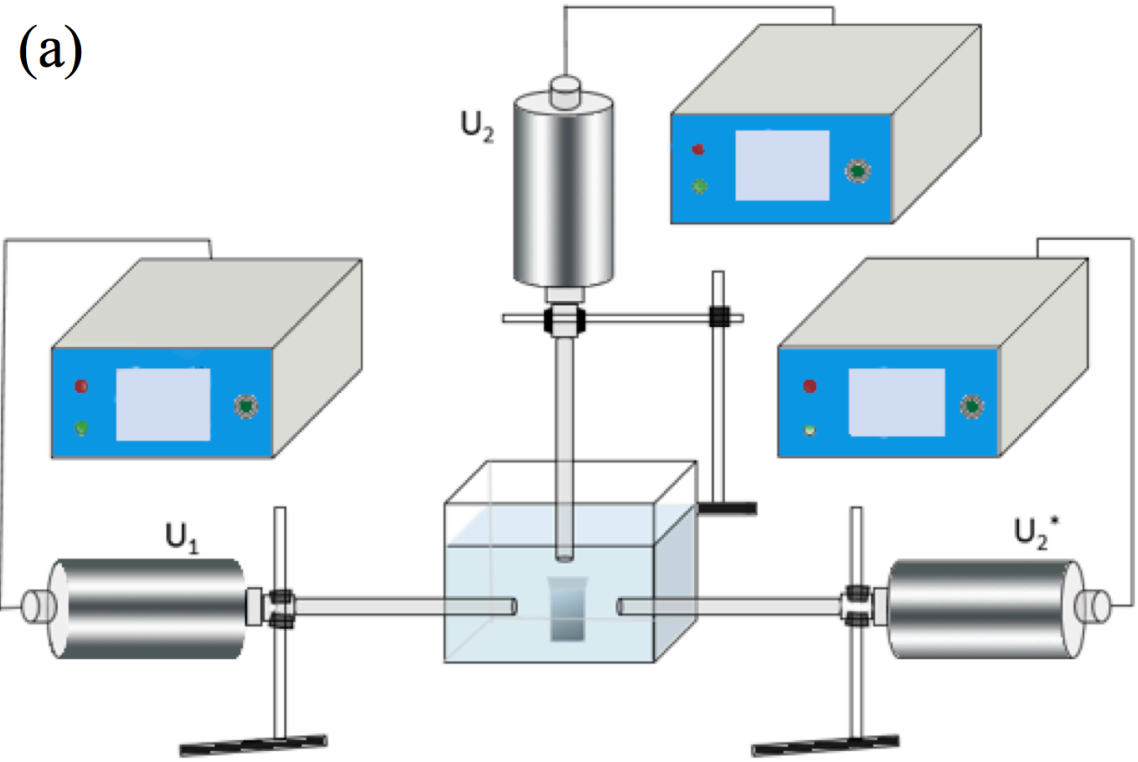

(b)

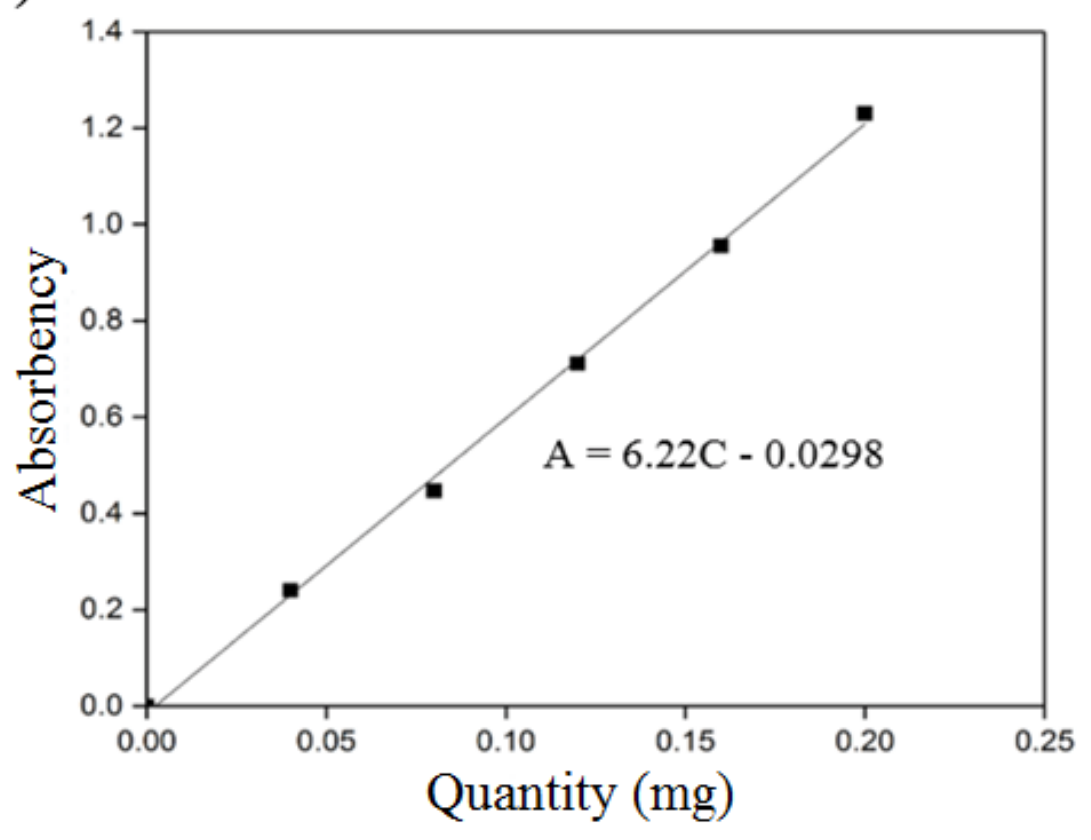

Figure 1 

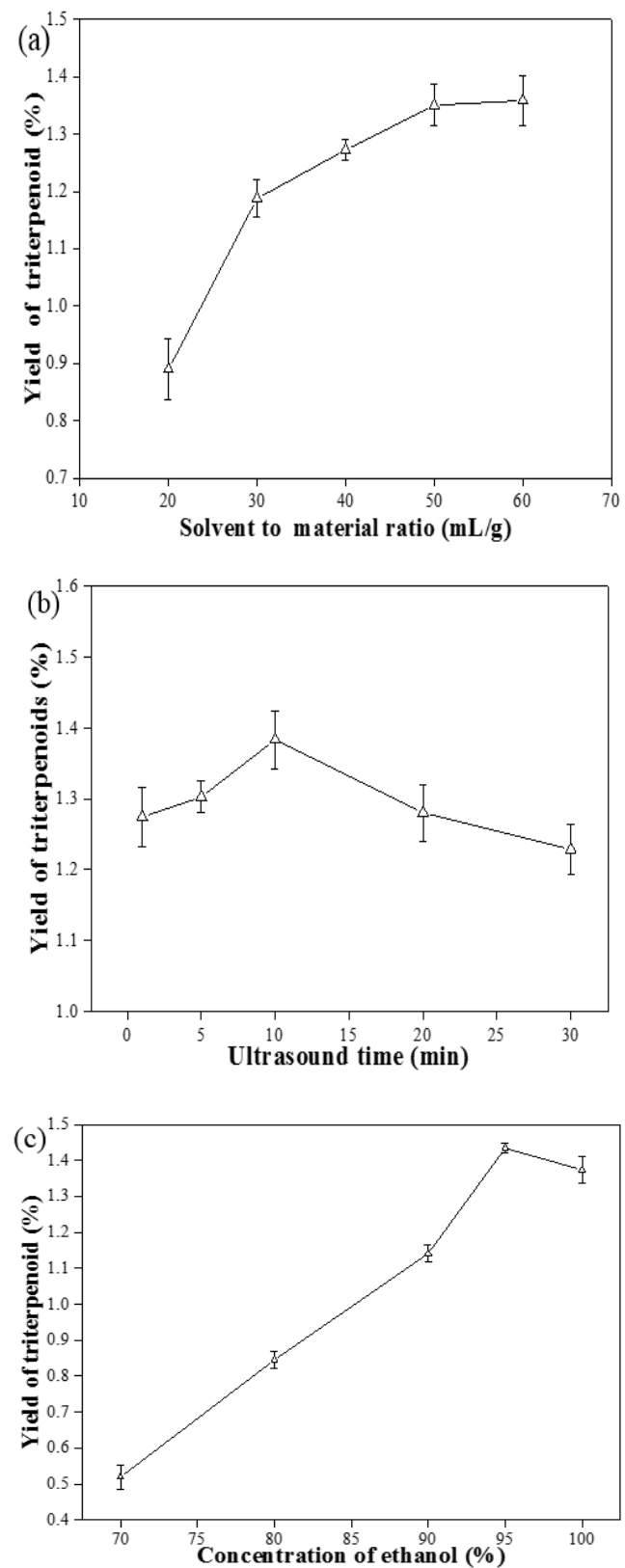

Figure 2 


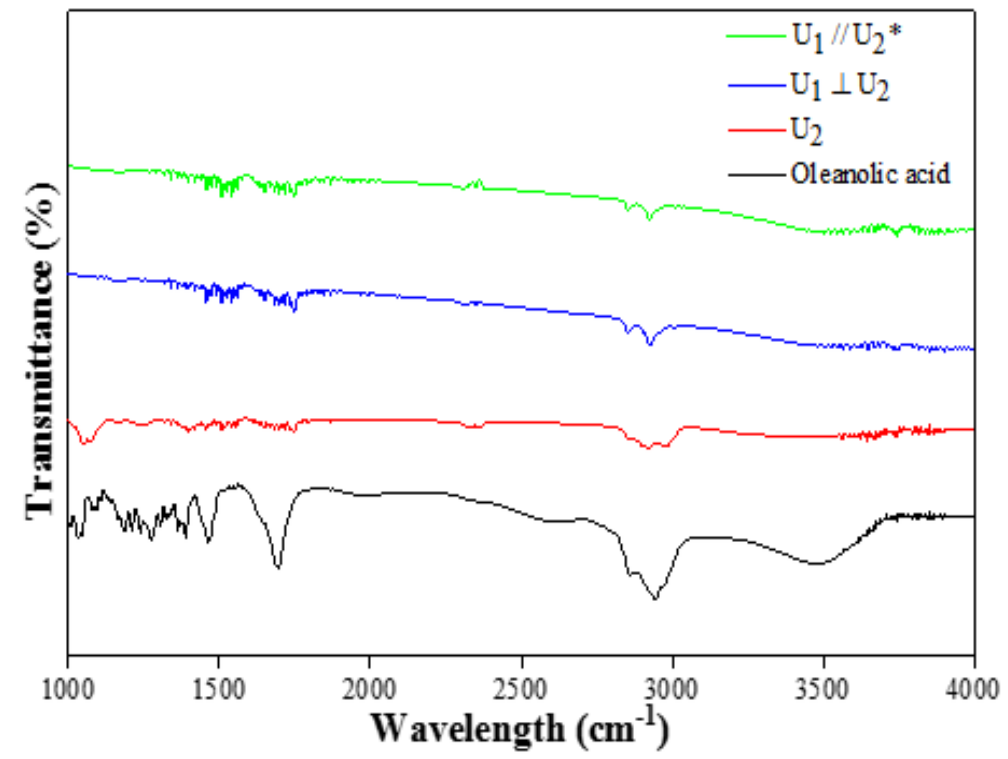

Figure 3 

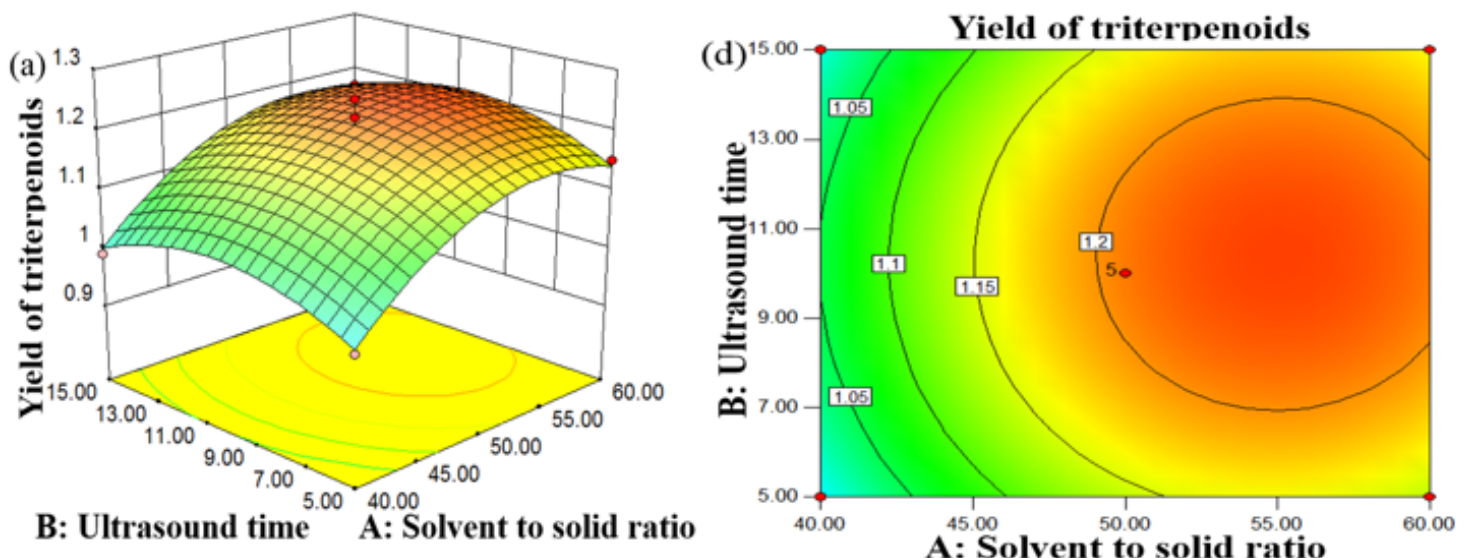

B: Ultrasound time A: Solvent to solid ratio
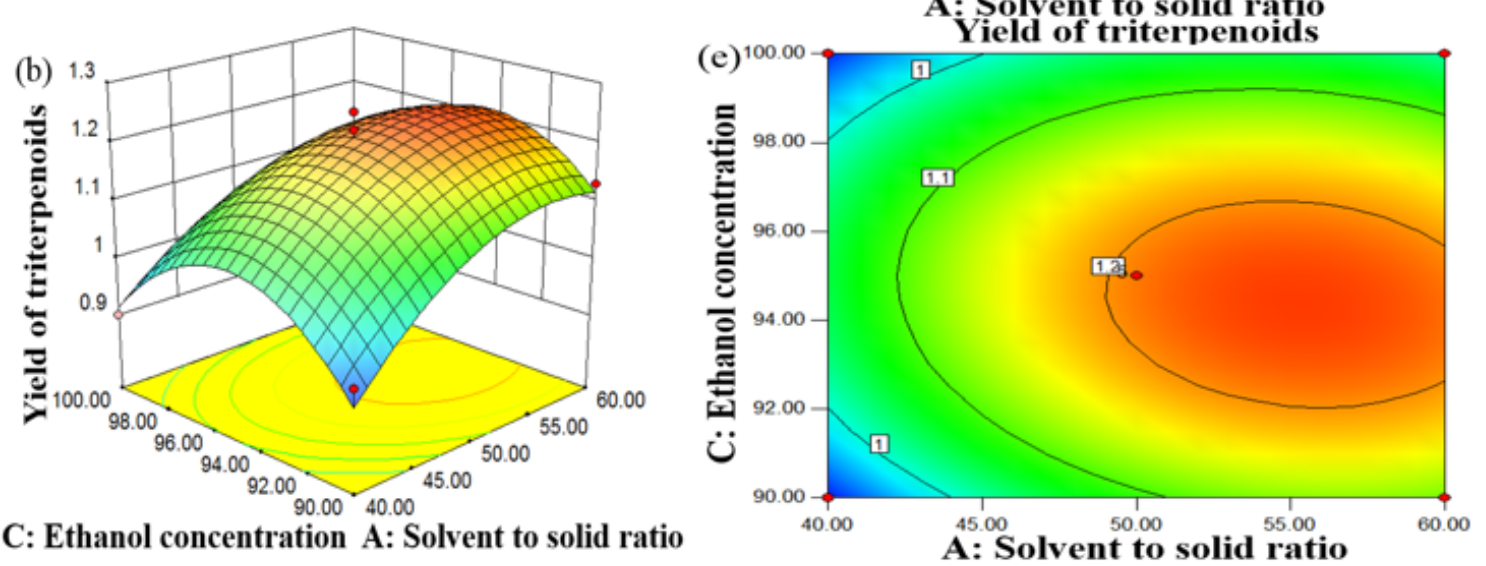

C: Ethanol concentration A: Solvent to solid ratio

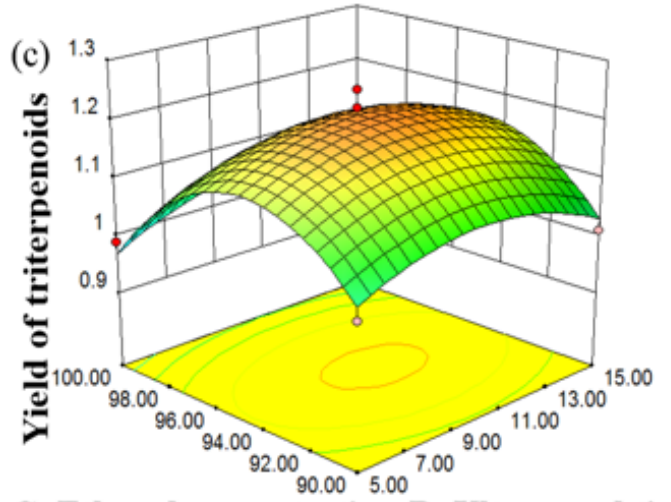

C: Ethanol concentration B: Ultrasound time

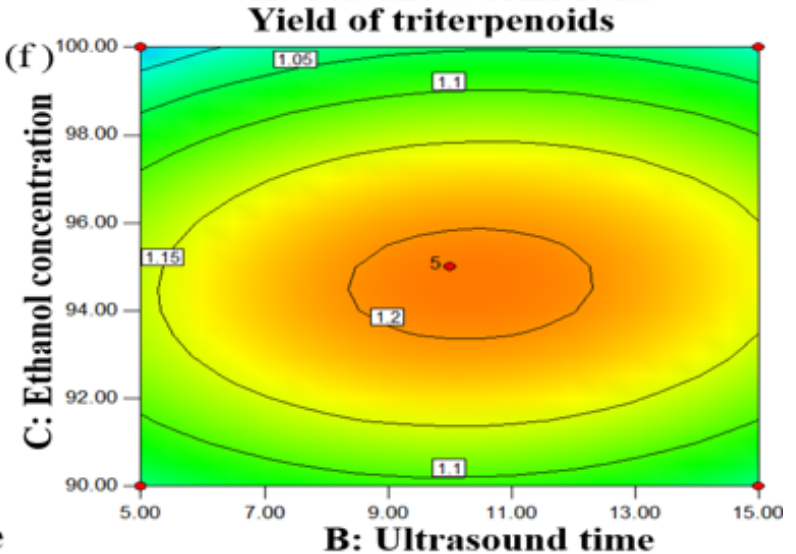

Figure 4 

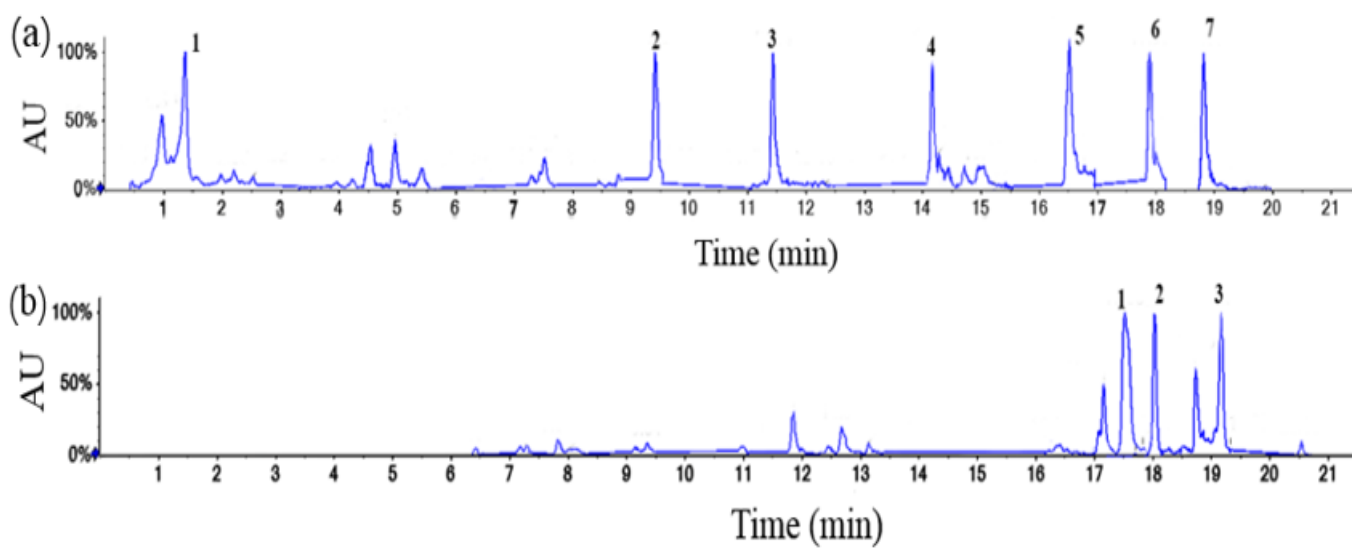

Figure 5

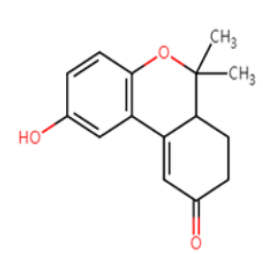

ganocochlearin B
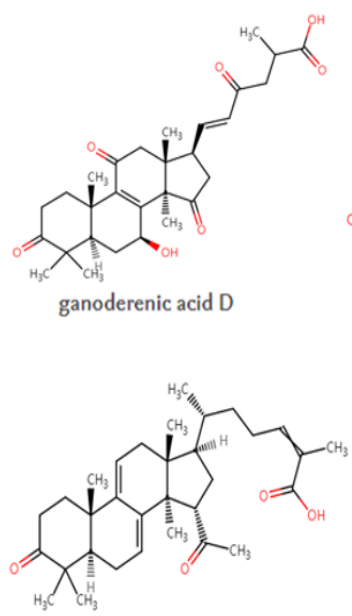

ganodermic acid TQ

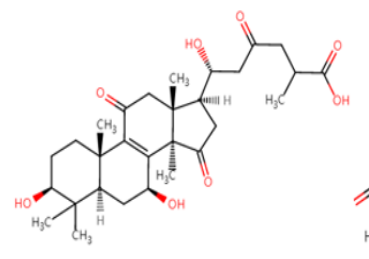

ganoderic acid I
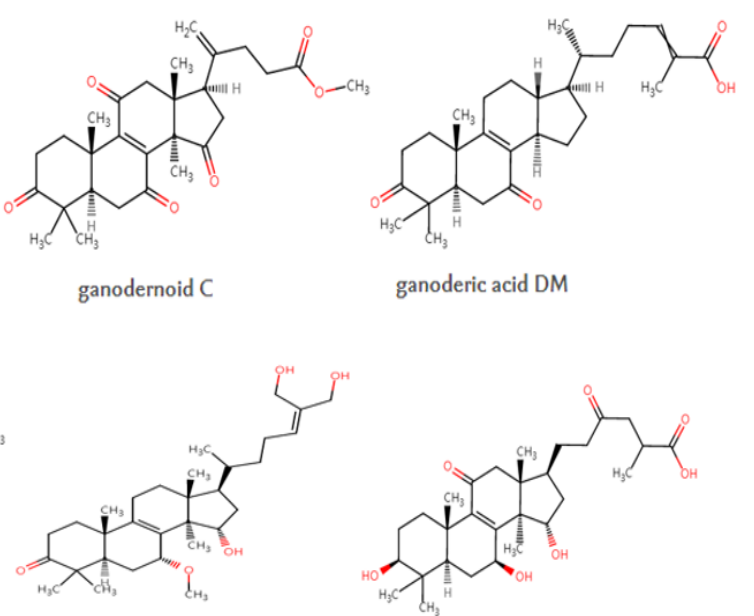

ganoderiol I ganoderic acid DM

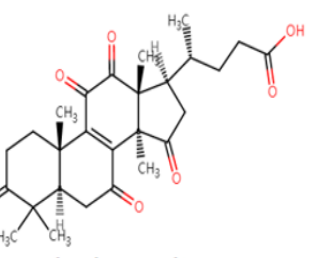

lucidenic acid D

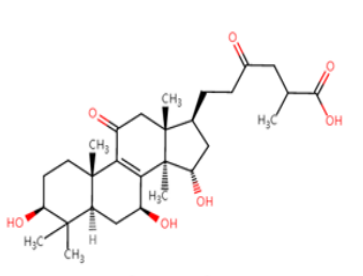

ganoderic acid C2

Figure 6

36 


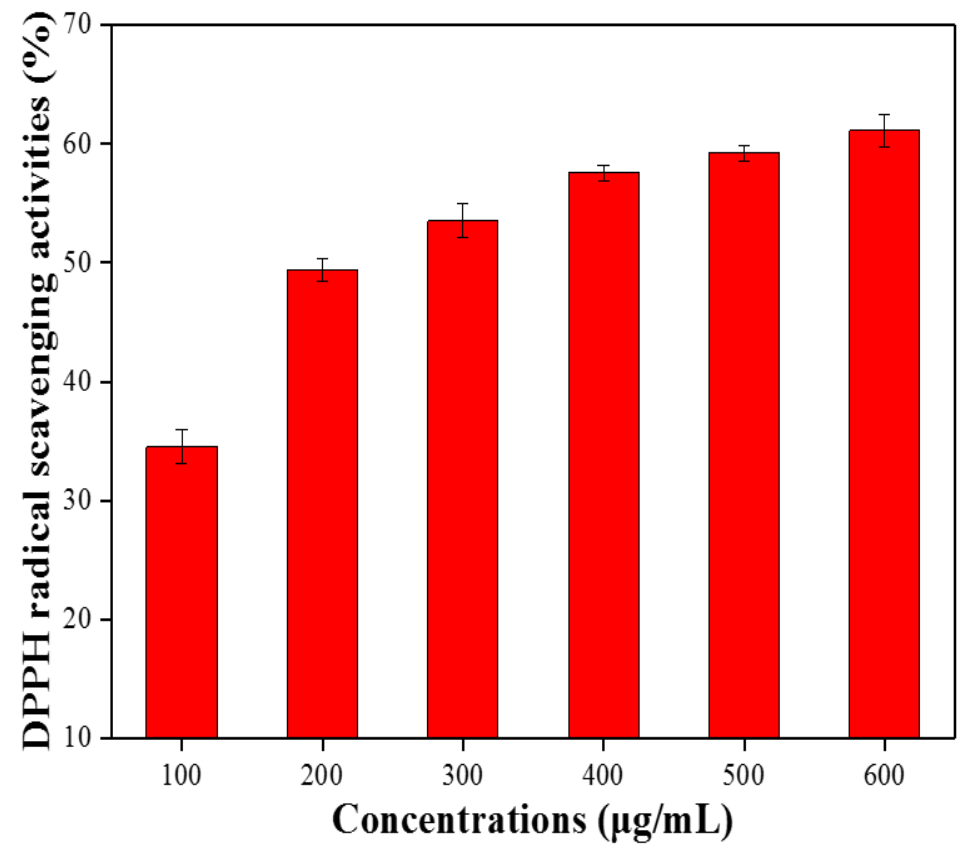

Figure 7 

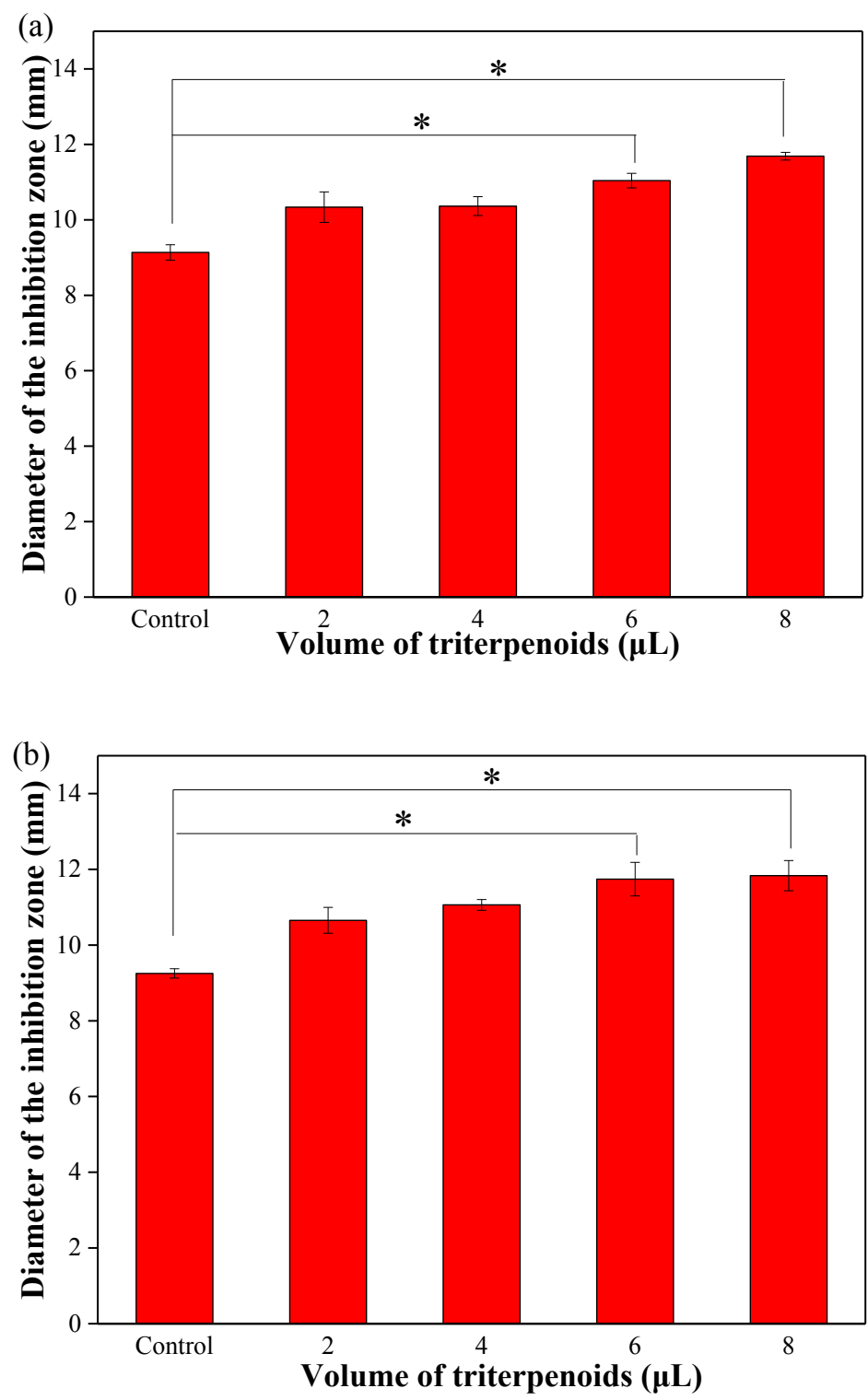

Figure 8 


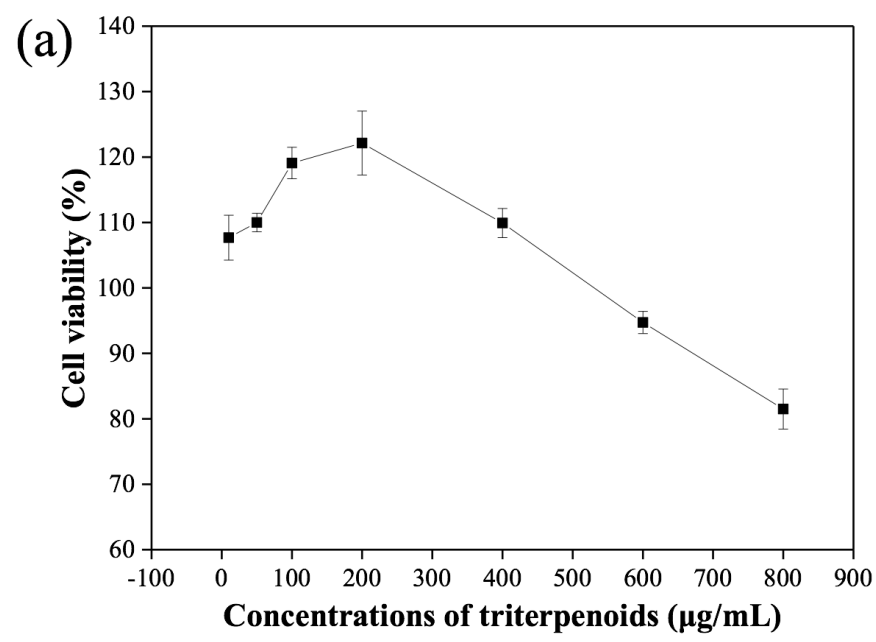

(b)
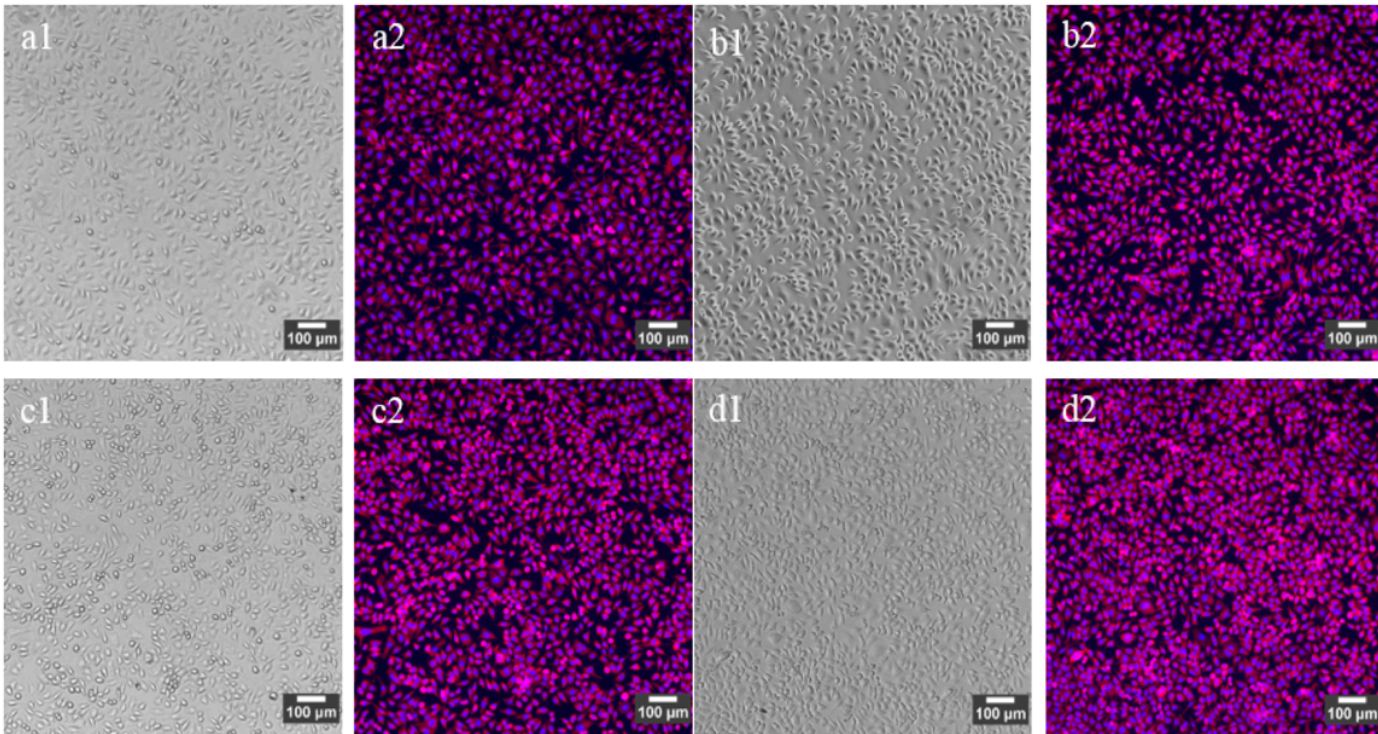

dI
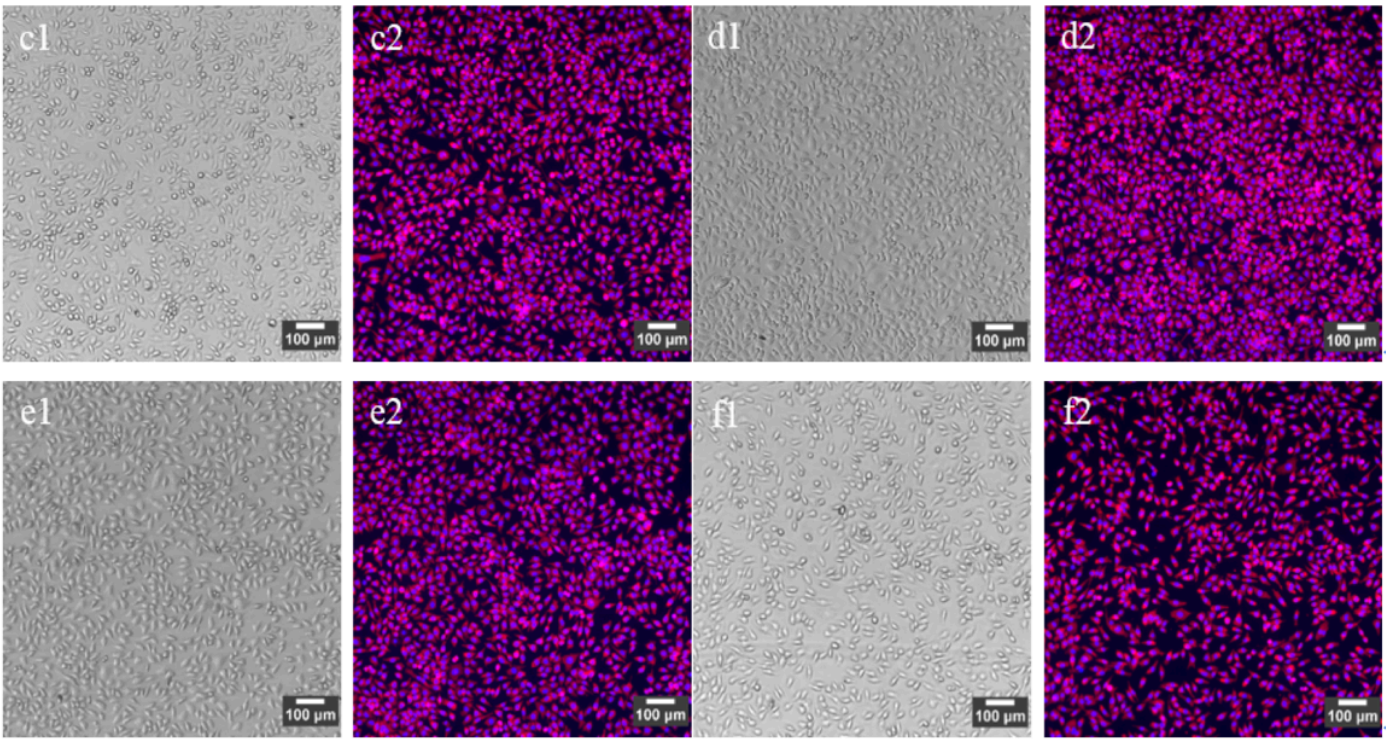

Figure 9 


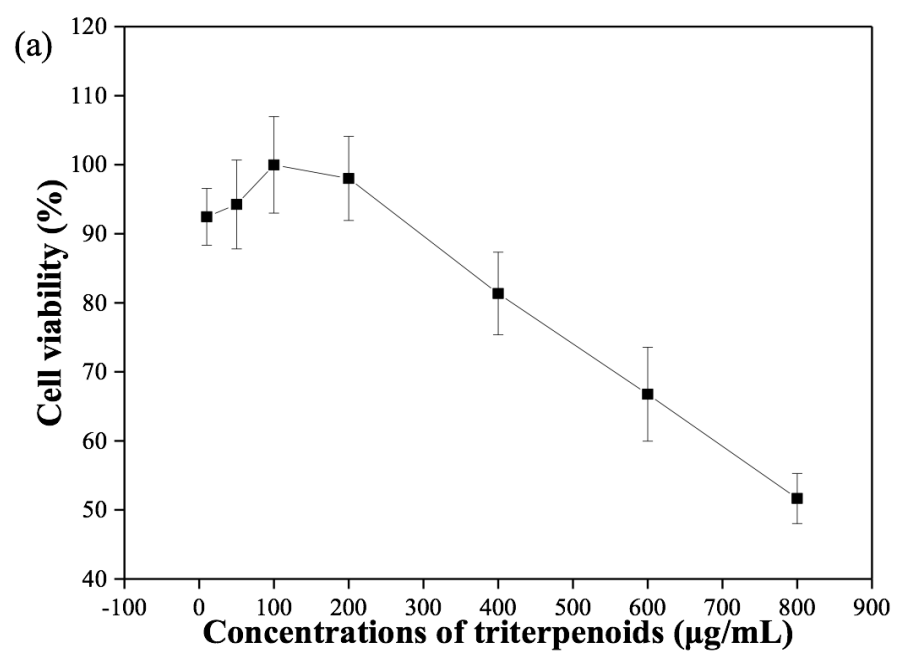

(b)
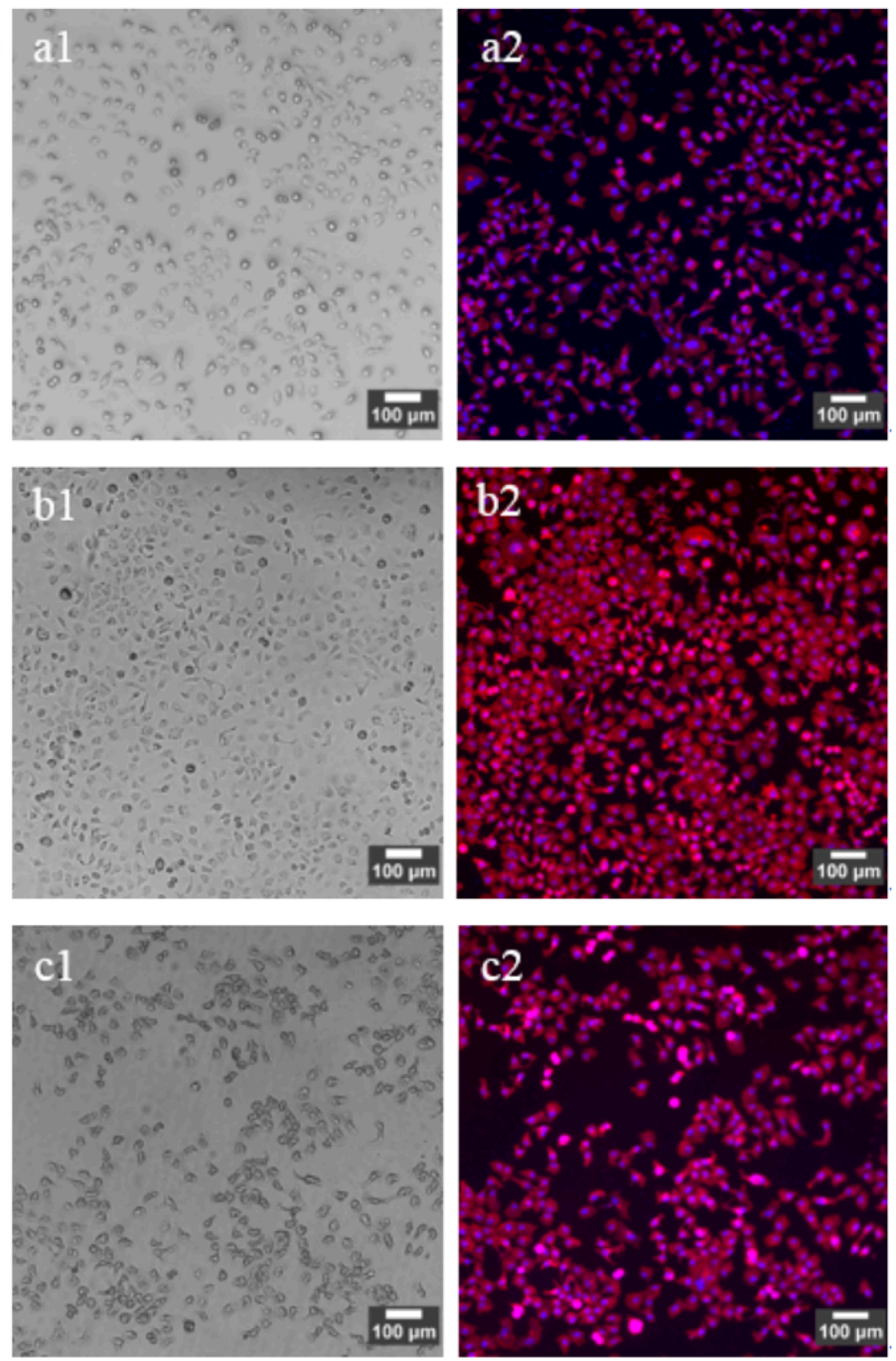

Figure 10 